\title{
V. Los Circuitos de la Droga. Sus Repercusiones en el Mundo Contemporáneo
}

\begin{abstract}
Germán GUILLÉN LóPEZ* e Israel Alvarado MARTínez

"La mercancía debe llegar a manos del comprador sin dejar rastro del recorrido, debe de llegar a su almacén de prisa, inmediatamente, antes de que el tiempo pueda empezar a pasar, el tiempo que podría permitir su control. Toneladas de mercancía se mueven como si fueran un paquete contra reembolso entregado a domicilio por el cartero...". Roberto Saviano (Gomorra).

Sumario: 1. Las principales rutas del tráfico de estupefacientes, A) Ruta de la Heroína, B) Ruta de la cocaína, C) Ruta del cannabis o sus derivados, D) Ruta para otros psicotrópicos; 2. Los efectos del tráfico de drogas: sus repercusiones en el mundo y su virtualidad criminógena, A) Los efectos negativos del tráfico de drogas en el mundo contemporáneo, A.1) Los capitales de la droga: un peligro para las instituciones financieras y políticas del mundo, B) El tráfico de drogas un germen que se alimenta de la crisis económica del tercer mundo, C) Los beneficios económicos del tráfico de drogas son una sombra para el sistema financiero internacional, D) El narcotráfico se filtra en las actividades del Estado y en los
\end{abstract} procesos de privatización de sus empresas; 3. Conclusiones; 4. Bibliografía.

\section{Principales Rutas del Tráfico de Estupefacientes}

Cada una de las sustancias ilícitas de mayor consumo a nivel mundial posee sus propios recorridos. Su particular tráfico se inicia en regiones en las que se cultiva y produce la droga, pasando por naciones que son zonas de paso - o tránsito-, para finalmente llegar a los países de gran consumo. En la mayoría de los casos, como ocurre con la heroína, la cocaína, el hachís y algunos psicotrópicos, estas trayectorias cruzan miles de kilómetros - océanos y continentes- para llegar a su destino final ${ }^{30}$.

El impacto económico, político y social que tienen las millonarias ganancias que provienen de los circuitos ilícitos de los estupefacientes no tiene precedentes, tampoco la repercusión - de ese mercado clandestino- a nivel mundial. En el presente, existen rutas especiales para llevar la droga a las manos del consumidor en donde quiera que éste se encuentre. Desde hace tiempo, existen circuitos que, de forma ex profesa, son aprovechados por las organizaciones criminales para alimentar el consumo internacional de los narcóticos. Sin la concurrencia de tales senderos clandestinos la mundialización y el éxito del tráfico de drogas ilícitas no podría tener -en términos creíbles- una correcta explicación.

\section{A. Ruta de la Heroína}

* Doctor en Derecho por la Universidad de Salamanca (España); Maestro en Ciencias Penales por el Instituto Nacional de Ciencias Penales (INACIPE), Miembro del Sistema Nacional de Investigadores, Profesor con reconocimiento de Perfil Deseable (PROMEP); Registrado como docente en la Academia Nacional de Seguridad Pública; Profesor Investigador de la Universidad de Sonora (México), germangl@sociales.uson.mx.

Profesor Investigador Invitado del INACIPE. Investigador Nacional Nivel I del Sistema Nacional de Investigadores (SNI). Ha sido Consultor de la Comisión para la Cooperación Ambiental de América del Norte (CCA), israel.alvarado@inacipe.gob.mx.

${ }^{30}$ Las rutas elegidas por los traficantes para trasladar sus sustancias tóxicas obedecen, básicamente, a dos circunstancias: 1ạ) son consideradas más seguras para trasladar la droga, y $2^{2}$ ) atienden a las leyes del mercado específico al que van destinadas. Vid. Herrero Herrero, César, «Criminología. Parte General y Especial», 1a y 2a ed., Dykinson, Madrid, 1997 y 2001, p. 551. 
Tiene su inicio principalmente en tres zonas o regiones de producción:

1a. Zona del "Triángulo de Oro», región compuesta por varios países asiáticos - donde proviene la mayor producción de heroína en el mundo- ${ }^{31}$ y se localiza en el espacio fronterizo del norte de Tailandia, algunos extremos de Birmania, $\mathrm{China}^{32}$ y Laos $^{33}$. La heroína producida es de color amarillento y se distribuye a través de Hong-Kong, Singapur y Bangkok, básicamente, por vía aérea, a los mercados de Estados Unidos, Europa Central y también al Reino Unido ${ }^{34}$.

2a. Zona de la "Media Luna de Oro» o del "Creciente Dorado»: la conforman países productores del sureste asiático: Pakistán, Irán y Afganistán, de donde proviene la heroína que más se decomisa en España $^{35}$. La droga recorre camino desde su lugar de origen, transitando, mayormente, a través de Turquía y la llamada «Ruta de los Balcanes», para llegar a los mercados de consumidores de Europa Occidental ${ }^{36}$.

3a. Zona de México: en esta región se produce menos heroína que en las anteriores, la mayor parte de la heroína se produce en México ${ }^{37}$ y Colombia, aunque también la producen otros países andinos ${ }^{38}$, la droga tiene como destino el mercado estadounidense, entrando - principalmente- por los estados del oeste y los aeropuertos de Nueva York y Miami. Las modalidades de traslado del producto tóxico más utilizadas son la «ingestión» y el transporte oculto en el cuerpo humano ${ }^{39}$.

En España, la heroína llega a través del tráfico ilícito que protagonizan las mafias de origen turco a través de la ya mencionada "Ruta de los Balcanes». Aunque últimamente se ha comprobado la participación en este tráfico ilegal de vasallos guineanos, nigerianos y ghaneses, representando una actividad considerable en las Islas Canarias. Gran parte de la heroína que se introduce al país es

${ }^{31}$ En concreto $60 \%$ de la producción mundial, distribuyéndose el otro porcentaje de la producción en diversos países: $17 \%$ en Pakistán, India y Afganistán $8 \%$, Turquía $5 \%$ y el resto en México. Vid. LLORENS BorRÁs, José Antonio, «La Droga y su Problemática Actual», Acervo, S. L., Barcelona, 1986, p. 28.

${ }^{32}$ Aunque es poca la heroína de origen chino que se decomisa en el continente europeo comparada con la que procede del subcontinente Índico, Europa es una diana cada vez más atractiva para los países que la suministran. La heroína China podría aparecer de nuevo rápidamente a medida que los traficantes intentan controlar parte del mercado establecido (Vid. STOCKLEY, David, «Drogas. Guía ilustrada», Edex, Bilbao, 1999, pp. 44 y 45). La posibilidad de que esto ocurra aumenta si tomamos en cuenta que quienes trafican con esta sustancia son las peligrosas Triadas. Vid. EsPINAzo GARcía, Juan, "La Droga. Perspectiva criminológica», Publicaciones del Instituto de Criminología de la Universidad Complutense de Madrid, 1980, p. 52.

33 LLORENS BORRÁS, José Antonio, «La Droga y su Problemática Actual», LLORENS BORRAS, José Antonio, «La Droga y su Problemática Actual», Acervo, S.L., Barcelona, p. 28.

${ }^{34}$ También, esta heroína se exporta vía aérea o marítima a estos mercados, a través de regiones occidentales del continente africano Vid. Herrero Herrero, César, "Criminología. Parte General y Especial», cit., p. 552.

${ }^{35}$ Vid. STOCKLEY, David, «Drogas. Guía ilustrada», cit., p. 44.

${ }^{36}$ En los últimos años las organizaciones mafiosas afganas, iraníes, paquistaníes y turcas han comenzado a abrir nuevas rutas que tienen como destino final Europa del Este y los Estados Unidos de Norte América, a través de nuevos Estados que provienen de la antigua URSS: Azerbayán, Georgía y Turkmenistán. Para movilizar la sustancia ilícita, comúnmente utilizan camiones TIR con matrícula turca. Las mafias turcas, son las que tienen prácticamente el monopolio del tráfico de la heroína destinada al mercado europeo.Vid. Herrero Herrero, César, "Criminología. Parte General y Especial», cit., p. 552.

${ }^{37}$ La heroína mexicana parduzca, llamada "lodo mexicano», comenzó a ser traficada en la década de los cincuenta, para los años setenta su tráfico ya estaba plenamente establecido. La ventaja de su traslado - a diferencia de la heroína asiática - es que ésta puede ser llevada a los EEUU por vehículo terrestre. Vid. GARcía RAMíREZ, Efraín, "Drogas. Análisis del delito contra la salud», SISTA, 3a ed., México, 1997p. 183.

${ }^{38}$ Desde hace algunos años, la heroína producida en los países andinos, comienza a encontrarse en los mercados negros de Europa y EEUU. Su presencia es cada vez mayor, y es resultado del incremento de los cultivos de amapola de opio en esas naciones. La mayoría de la heroína producida en esas regiones, es impura y contiene mezclas de diversas sustancias, algunas proceden del opio, otras del proceso de elaboración, así como ocasionalmente la introducción de otras sustancias (metacualona [hipnótico y sedante], paracetamol [un analgésico no opiáceo] y cafeína), las que se añaden después del proceso de fabricación, pero antes de que la droga sea enviada al país de destino. Vid. STOCKLEY, David, "Drogas. Guía ilustrada», cit., p. 45.

${ }^{39}$ Vid. Herrero Herrero, César, «Criminología. Parte General y Especial», cit., p. 552.

$$
\sim 31 \sim
$$


trasladada en coches pequeños, autobuses, e incluso, en camiones TIR provenientes de Alemania, Italia y Holanda, que acceden a España a través de La Junquera e Irán ${ }^{40}$.

\section{B. Ruta de la Cocaína}

La cocaína se adquiere de la planta de la coca (erythroxylum coca) que se da pródigamente en las zonas accidentadas de Sudamérica como Colombia, Perú, Bolivia ${ }^{41}$ y Brasil, y también en casos aislados como Taiwan, Java, India y algunas regiones del continente africano ${ }^{42}$. La mayor parte de la producción a nivel mundial es procesada en laboratorios de Colombia debido a su factor productivo ${ }^{43}$, su condición como centro privilegiado del contrabando ${ }^{44}$, que ese país cubre $70 \%$ del mercado estadounidense -el mayor país comprador y consumidor de cocaína en el mundo- y a que los cárteles colombianos de la droga manejan el mercado exterior que se dirige a Europa ${ }^{45}$.

En lo relativo al transporte al por mayor de cocaína de Colombia a la Unión Americana, cabe decir que esta actividad se ha convertido en una de las acciones ilícitas más lucrativas que ha instaurado el narcotráfico en ese país, materia que no solamente se ha cristalizado como una indiscutible especialidad en el tráfico de drogas, sino incluso como una actividad independiente. El pago que se hace por el transporte de un kilogramo de cocaína de Colombia a Estados Unidos tiene un precio que ronda entre los tres mil y seis mil dólares, el cual es pagado con droga al precio de Colombia, circunstancia que en cierta forma ha contribuido a bajar la cotización de la coca en ese país americano.

Por lo que toca a Europa, se subraya que numerosas son las vías que utilizan los narcotraficantes para enviar la cocaína al viejo continente, entre ellas, algunas tradicionales que parten de la costa colombiana: Bogotá-Estados Unidos-Europa; Perú-Bolivia-Europa; y, Bogotá-Europa ${ }^{46}$. Igualmente, pueden encontrarse rutas de creación reciente que parten de puertos ubicados en Venezuela, Surinam, Panamá y

${ }^{40}$ Ob. ult. cit.

${ }^{41}$ La hoja de coca es de una gran importancia para Perú y Bolivia. Posee, primeramente, un valor tradicional y cultural, pues desde siglos ha sido utilizada por los indios andinos en sus ceremonias religiosas y se mastica en algunas comunidades autóctonas para efectos terapéuticos, sensación de bienestar, resistencia al cansancio y al hambre (Vid. LLORENS BoRRÁs, José Antonio, «La Droga y su Problemática Actual», cit., p. 36). En la actualidad su papel va más allá de estos roles, pues el arbusto del que se obtiene la coca cuenta con otros valores que superan los ámbitos mencionados. En el presente, es indiscutible su influencia en los ramos económico, social y político. Esto lo decimos, al interpretar los datos aportados por un miembro del Comité de Coordinación de la Federación de Campesinos Productores de Coca del Chapare (Bolivia), compuesta por 6 Federaciones que albergan 70,000 familias, opinión e información que transcribimos a continuación: «La crisis económica que atraviesan nuestros países es soportada por la existencia de la coca, que permite a nuestra familia campesina sobrellevar la baja en el precio de otros productos agrícolas, dándonos estabilidad. Los relocalizados mineros, fabriles y constructores vuelven a las tierras para sembrar coca como su única alternativa de supervivencia. En Perú, la coca representa $25 \%$ de las exportaciones. En Bolivia, es $40 \%$. Si Bolivia tiene una significación económica es gracias a la coca. Aquí cabe señalar que, aunque estas sumas de dinero son de gran importancia para nuestros países $85 \%$ de las ganancias de las drogas se quedan en los países del Norte». Vid. HerRadA, David., "Con la hoja de coca combatimos el hambre», en: Drogas, Desarrollo y Estado de Derecho, Instituto Deusto de Drogodependencias, Universidad de Deusto, Bilbao, 1995, p. 55.

${ }^{42}$ Vid. STOCKLEY, David, «Drogas. Guía ilustrada», cit., p. 72.

${ }^{43}$ Que radica, primordialmente, en la dinámica que se sabe imprimir a su comercialización, en la movilidad de sus excedentes, a su avanzada tecnología y a la permisibilidad social que muestra a los traficantes que residen en su territorio. Cf. ESPINAZO GARCía, Juan y Molina ESTRELLA, Araceli, «Dimensiones del narcotráfico internacional», editora Araceli Molina estrella, Madrid, 2001. p. 128.

${ }^{44}$ Esto debido, entre otras circunstancias a: 1) su disponibilidad en el terreno, perfecto para el cultivo; 2) ideal ubicación geográfica para el contrabando de drogas en grandes cantidades a EEUU a través del Caribe; 3) corrupción estatal; 4) vocación de violencia en todas sus formas; 5) pobreza, y 6) ineficacia de las instituciones gubernamentales, en Antioquia y Medellín se despliega el principal polo mundial del narcotráfico, por mencionar algunas. Vid. ESPINAZO GARCíA, Juan y MolinA ESTRELLA, Araceli, «Dimensiones del narcotráfico internacional», cit., pp., 5 y 6.

${ }^{45}$ Vid. Prado SaldarRIAGA, Víctor, "La política criminal y el problema de la droga en Perú», en La actual política criminal sobre drogas. Una perspectiva comparada, José Luis Díez Ripollés y Patricia Laurenzo Copello (cords.), Tirant lo blanch, Valencia, 1993, pp. 150 y ss.

${ }^{46}$ Vid. ESPINAZO García, Juan y Molina ESTRELLA, Araceli, «Dimensiones del narcotráfico internacional», cit., p. 7. 
Brasil $^{47}$. Cabe recalcar que en los últimos años los cárteles colombianos de la droga han ampliado sus mercados ilícitos a Japón, Filipinas, Nueva Zelanda, Hong-Kong y Corea ${ }^{48}$.

La Península Ibérica, debido a su situación geográfica -así como por otros aspectos de carácter cultural y lingüístico-, ha sido utilizada por los narcotraficantes como punto de entrada y de almacenamiento para la cocaína procedente de los países sudamericanos ${ }^{49}$; también, como plataforma estratégica para la redistribución de la droga a los demás países de Europa Occidental ${ }^{50}$.

Recientemente, junto al envío de la sustancia ilícita ya elaborada $-y$ lista para su venta en el mercado-, los cárteles de la droga realizan exportaciones a la península de pasta de coca para que sea procesada en laboratorios clandestinos establecidos en España e Italia, a efecto de subsanar las dificultades que tienen para la adquisición de precursores químicos ${ }^{51}$.

Por otro lado, también resulta preocupante que los traficantes de estupefacientes sudamericanos, aprovechando los cambios políticos, económicos y sociales de los antiguos países pertenecientes a la desaparecida Unión Soviética utilicen, con apoyo de organizaciones criminales autóctonas, puertos y aeropuertos internacionales de esas regiones como bases operativas para la distribución de la cocaína a diversos mercados europeos ${ }^{52}$.

Un informe de la Dirección General de Policía de España, con respecto a sus actuaciones de combate al tráfico de cocaína en $1998^{53}$, muestra que en España los traficantes colombianos, con ayuda de traficantes gallegos, introducen por vía marítima grandes cantidades de esa droga. El procedimiento es el mismo que se utiliza hace años, con una gran preeminencia de los envíos mediante contenedores, a través de operaciones de importación y exportación organizadas con empresas de transporte ${ }^{54}$. El envío aéreo mediante «mulas» sigue teniendo importante afluencia, como lo demuestran los $\mathbf{3 7 6}$ kilogramos de cocaína decomisada por el Cuerpo Nacional de Policía en los distintos aeropuertos españoles durante el año, y las 204 detenciones llevadas a cabo en estos recintos ${ }^{55}$.

\section{C) Ruta del Cannabis o sus Derivados}

${ }^{47}$ Vid. Herrero Herrero, César, «Criminología. Parte General y Especial», cit., p. 553.

${ }^{48}$ Ob. ult. cit.

${ }^{49}$ Por otra parte, algunos opinan que el papel de la península con relación al tráfico de cocaína ya ha superado, desde hace tiempo, el compromiso vinculado únicamente a su situación geográfica. Hay quien afirma que los traficantes de drogas - sean colombianos, peruanos o bolivianos - junto a sus actividades de tráfico ilícito de drogas, forman ejércitos privados de mercenarios en suelo español bajo la tapadera de empresas de seguridad. Cf. RotH, Jürgen y FREY, Marc, "Europa en las garras de la mafia», Anaya \& Mario Muchnik, Madrid, 1992, p. 362.

50 Vid. GARZón, Baltasar y MEGíAs, Eusebio, «Narco. El tráfico de drogas como instrumento del crimen organizado. La presencia de las drogas: razones, riesgos y límites», Germania, Barcelona, 1997, p. 49; Herrero Herrero, César, "Criminología. Parte General y Especial», cit., p. 553; ESPINAZO GARCíA, Juan y MolinA ESTRELLA, Araceli, «Dimensiones del narcotráfico internacional», cit., p. 40.

${ }^{51}$ Vid. Herrero Herrero, César, «Criminología. Parte General y Especial», cit., p. 553.

${ }^{52}$ Ob. ult. cit.

${ }^{53}$ Unidad Central de Estupefacientes, «Actuaciones del Cuerpo Nacional de Policía. Tráfico de drogas. 1998», en: CPol., No. 47, Instituto de Estudios de policía, Dirección General de Policía, Madrid, marzo-abril de 1999, p. 106.

${ }^{54}$ Un informe del CNP, presentado por su Unidad Central de estupefacientes, "Análisis actual del tráfico de estupefacientes", Madrid, 1995, pp. 22-23, muestra que existen otros sistemas de transporte de cocaína que también tienen una importante afluencia, el más notorio de ellos, es el transporte de la droga en aguas internacionales en los llamados barcos nodriza hasta las inmediaciones de los litorales nacionales, para que lanchas rápidas se ocupen de alijarla en la costa. Otro procedimiento de envío de la droga que últimamente presenta un notorio incremento, es la utilización del Servicio Postal de Correos, a través del despacho de etiqueta verde, algunas organizaciones criminales remiten ciertas cantidades de cocaína. Informe cit. por: HERRERO HERRERO, César, «Criminología. Parte General y Especial», cit., p. 554.

${ }^{55}$ Unidad Central de Estupefacientes, «Actuaciones del Cuerpo Nacional de Policía. Tráfico de drogas. $1998 »$, cit., p. 106. 
La marihuana y el hachís son las drogas más «populares» extraídas del cannabis sativa ${ }^{56}$. La primera de las drogas es de gran consumo en el mercado norteamericano ${ }^{57}$, mientras que la segunda es más consumida en Europa y otras regiones del mundo ${ }^{58}$. Cada vez es más común que se trafique con aceite de hachís, en comparación de la marihuana y hachís tradicionales, ya que reduce el volumen, tiene una potencia superior, disminuye los riesgos de transporte y resulta más rentable económicamente ${ }^{59}$.

El cannabis crece tanto en zonas cercanas a España (norte de África [Marruecos]), como en regiones tan alejadas de sus fronteras (sureste asiático [Tailandia y Sri Lanka], suroeste asiático [Nepal y Pakistán] o en América [primordialmente en México, Colombia y Jamaica]) ${ }^{60}$. Por lo que toca a los cultivos de interior, los llamados cultivos hidropónicos, en España tienen poca afluencia, siendo más común este tipo de labranzas en naciones del centro de Europa como Holanda.

Los medios de transporte más empleados por los traficantes para trasladar los derivados del cannabis, principalmente hachís, son el terrestre (camiones) y el marítimo (yates) ${ }^{61}$. La mayoría del hachís incautado en España es originario del Norte de África, siendo Marruecos el mayor exportador y productor de esta droga. Las actuaciones de la policía española en contra del tráfico de esta droga se han dirigido, especialmente, a la captura y desmantelamiento de organizaciones criminales formadas por extranjeros y nacionales, y a las integradas únicamente por ciudadanos españoles ${ }^{62}$. Las nacionalidades extranjeras que inciden en estas organizaciones de delincuencia organizada, son la marroquí, la inglesa y la italiana ${ }^{63}$.

En nuestros días sigue siendo superior el consumo de hachís en comparación a las demás drogas. Los que trafican con esta sustancia siguen operando en las rutas tradicionales de introducción en España, con un ligero deslizamiento encaminado hacia el noreste de la costa mediterránea, la zona del Levante.

${ }^{56}$ Vid. LLORENS BORRÁs, José Antonio, «La Droga y su Problemática Actual», cit., p. 21.

57 Es tan fuerte la demanda en ese país, que tiene sus propios plantíos de marihuana, existen gran número de terrenos cultivados con plantas "sin semilla» de alta calidad, en la costa oeste y en especial en Hawai. Vid. GARcía RAMíREZ, Efraín, «Drogas. Análisis del delito contra la salud», cit., p. 181.

${ }^{58}$ Vid. STOCKLEY, David, «Drogas. Guía ilustrada», cit., p. 108.

${ }^{59}$ Cf. Espinazo García, Juan, «La Droga. Perspectiva criminológica», cit., p. 143.

${ }^{60}$ Estos países son protagonistas de un prodigioso negocio ilícito exportando toneladas de marihuana a la Unión Americana cabe señalar con respecto del caso mexicano, que la droga la encontramos en las laderas occidentales de la sierra madre, en Guerrero, Oaxaca y Michoacán, como en Sonora, Sinaloa y Durango. Son más de 3,000 km de frontera los que existen entre México y EEUU, por lo que prácticamente es imposible tener una vigilancia en todo ese espacio, lográndose en consecuencia, que pueda contrabandearse con las drogas de todo tipo. La marihuana que sale de México hacía los Estados Unidos de Norteamérica se acarrea en todo tipo de automóviles o bien por avión e inclusive en ciertos casos por barco, yéndose por carreteras donde se esquiva la vigilancia debido a que los vehículos están dotados de compartimientos secretos al igual que aviones y aeronaves, o bien utilizan rutas no transitadas y que carecen de vigilancia hasta llegar a su destino. En México, importantes organizaciones mafiosas de origen autóctono, desde hace décadas, exportan toneladas de cannabis en la modalidad de marihuana a EEUU. Durante los años setentas, estas organizaciones lograron grandes sumas de dinero producto de ese tráfico ilícito. Estos clanes criminales han consolidado un importante poder en algunas regiones del país. Algunos de ellos —en la actualidad- siguen enviando grandes cantidades de esa droga al mercado norteamericano y otros se han decantado por el tráfico de cocaína por considerarlo más atractivo. En lo tocante a la marihuana de Colombia, se siembra en la península de la Guajira la que cuenta con el suelo y condiciones climatológicas adecuadas para el cultivo de hierba de buena calidad, es de este sitio donde parte esta droga primordialmente a la Unión Americana y en menor cuantía a otras naciones de América. Las rutas del contrabando de la marihuana de Colombia, son similares a las de la cocaína, sin embargo las ganancias son mayores cuando el producto con el que se trafica es cocaína. Vid. GARcía RAmírez, Efraín, «Drogas. Análisis del delito contra la salud», cit., p. 181; PRIETO RODRíGUEZ, Javier Ignacio, "El delito de tráfico y el consumo de drogas en el ordenamiento Español», 2a ed., Aranzadi, Pamplona, enero de 1993, p. 643.

${ }^{61}$ El cannabis decomisado en España en el año 1997 por el Cuerpo Nacional de Policía procedía de 76 países. Vid. UNIDAD Central de Estupefacientes, "Actuaciones del Cuerpo Nacional de Policía. Tráfico de drogas. 1998», CPol. No. 47, Instituto de Estudios de policía, Dirección General de Policía, Madrid, marzo-abril de 1999, p. 90.

${ }^{62}$ Vid. MAPelli CafarenA, Borja; GonzÁlez CANo, Ma Isabel y Aguado CorreA, Teresa, «Estudios sobre la delincuencia organizada. Medios, instrumentos y estrategias de la investigación policial», Instituto Andaluz de Criminología/Mergablum, Sevilla, 2001, p. 80.

${ }^{63}$ Vid. UnidAd Central De EstupefaCIenTES, «Actuaciones del Cuerpo Nacional de Policía. Tráfico de drogas. $1998 »$, cit., p. 95. $\sim 34 \sim$ 
Igualmente, se da la presencia de otro tráfico - que va más allá del consumo nacional-, como es el caso del que procede del norte de África y que transita por España con destino a países del centro de Europa. ${ }^{64}$

\section{D) RUTA PARA OTROS PSICOTRÓPICOS}

En la lista I del Convenio de Naciones Unidas de 1971 sobre Sustancias Psicotrópicas (Viena, 21 de diciembre), figuran todas las sustancias de este tipo que se consideran prohibidas, pero solo nos referiremos al MDMA (Éxtasis), speed y el LSD, por ser las más conocidas en el mercado español ${ }^{65}$. Estas drogas de síntesis - derivadas de la metacualona- son elaboradas principalmente en Holanda y en la costa oeste de Estados Unidos ${ }^{66}$. La proliferación de su consumo y lo peligroso de sus efectos, hacen que, entre las drogas prohibidas, sean las que causen mayor alarma a nivel internacional ${ }^{67}$.

En lo correspondiente al MDMA (Éxtasis) y al speed, la mayor parte de lo que se consume en suelo español es de origen holandés. Las sustancias psicotrópicas son introducidas al país por vía terrestre utilizando el sistema de carreteras, tanto en transportes privados como comerciales, vehículos en los que viene oculta la droga tanto en huecos naturales como preparados en el equipaje o entre las ropas de sus ocupantes $^{68}$.

Por otro lado, con el LSD -el de mayores efectos y que en su momento fue el más difundido $-{ }^{69}$, no hay una exactitud con respecto a su procedencia y origen, pero se considera que la mayoría procede de los Países Bajos ${ }^{70}$, y al igual que los otros dos psicotrópicos es introducido a España en todo tipo de automóviles ${ }^{71}$.

El mercado ilícito español de la oferta y demanda de psicotrópicos, responde en términos generales a las mismas características observadas en los mercados de su entorno geográfico, aunque con menor consumo y mínima producción ${ }^{72}$ que en el Reino Unido, los Países Bajos y Bélgica. Además, el mercado negro de estas sustancias en el país no es homogéneo, como lo es en los países anteriormente citados, ya que el mismo se centra particularmente en ciertas regiones peninsulares, grandes ciudades e insulares donde existe mayor presencia del turismo europeo.

Es difícil determinar con precisión los niveles de demanda que este tipo de drogas tienen dentro del territorio español, debido a las especiales características que presenta su tráfico ilícito. ${ }^{73}$ Pero lo que sí se puede precisar son las regiones donde se estima su mayor afluencia, v.g., el tráfico de MDMA continúa situándose en todo el Levante español, en las Islas Baleares, Canarias e Ibiza, en las que se han llevado a cabo grandes decomisos de dicha sustancia por parte del CNP ${ }^{74}$.

${ }^{64}$ Ob. ult. cit.

${ }^{65} \mathrm{Vid}$. UnidAd Central de EstupefacienteS, «Actuaciones del Cuerpo Nacional de Policía. Tráfico de drogas. 1998», cit., p. 103.

${ }^{66}$ Esconotado, Antonio, «Historia de las Drogas», tomo III, Alianza, Madrid, España. 1989, pp. 245 y ss.

${ }^{67}$ STOCKLEY, David, «Drogas. Guía ilustrada», cit., p. 31.

${ }^{68}$ Vid. Unidad Central de Estupefacientes, «Actuaciones del Cuerpo Nacional de Policía. Tráfico de drogas. 1998», cit., pp. 127 y

134.

${ }^{69}$ LLORENS BORRÁS, José Antonio, «La Droga y su Problemática Actual», cit., p. 44.

70 UnIDAD Central De ESTUPEFACIENTES, «Análisis actual del tráfico de estupefacientes», Madrid, 1995, p. 120. Cit. por: HeRrero HerRero, César, «Criminología. Parte General y Especial», cit., p. 555.

${ }_{71}^{7}$ UnIDAd CentRAL De EstuPEFACIENTES, «Actuaciones del Cuerpo Nacional de Policía. Tráfico de drogas. 1998», cit., p. 139.

72 A España no se le considera todavía como un país productor, aunque sí se han desmantelado algunos laboratorios consagrados especialmente al encapsulado o a la elaboración de pastillas con materias primas procedentes de terceros países. UNIDAD Central de EstupefaCientes, «Actuaciones del Cuerpo Nacional de Policía. Tráfico de drogas. 1998», cit., p. 141.

${ }^{73}$ Las circunstancias particulares a las que nos referimos son básicamente: la presencia de distintos perfiles de consumidores y traficantes; poca delincuencia derivada o que se origine con este tráfico y consumo; las dificultades que presenta la actividad represora policial dirigida contra los centros de distribución de estas drogas o a la existencia de otras sustancias con composición química que no responden a una fórmula química concreta a las que se les denomina éxtasis sin serlo, Ob ult. cit.

${ }^{74}$ Ob. ult. cit. 
Revista Jurídica del Departamento de Derecho Academia de Derecho Administrativo

Tercera Época Año2. No. 3 / Julio-Diciembre 2010

\section{Los Efectos del Tráfico de Drogas: sus Repercusiones en el Mundo y SU VirTualidad CRiminógena}

Es evidente que desde el punto de vista estrictamente penal - realidad jurídica, del deber ser, cubierta de aspectos axiológicos y valorativos $-{ }^{75}$, las conductas ilícitas vinculadas con los delitos de tráfico de drogas atentan directamente al bien jurídico de la salud pública. También lo es, que desde la perspectiva criminológica - realidad empírica, fáctica, del ser- ${ }^{76}$ dichas acciones prohibidas acarrean una serie de consecuencias distintas a la tutela de este valor jurídico, ligadas a las motivaciones que le dieron su origen; es decir, a los deseos de los narcotraficantes de obtener altos beneficios económicos mediante la ejecución de estas actividades criminales, en las que se explota la dependencia y habitualidad causadas por el consumo de drogas ${ }^{77}$.

La expectativa criminal de obtener elevadas ganancias monetarias por actos ligados al tráfico de drogas, provoca una cadena de acontecimientos que generan un particular y peligroso ambiente criminógeno en la mayor parte de las acciones relacionadas con el comercio ilícito de estupefacientes. Junto a esa visión delictiva - de obtener grandes beneficios económicos- encontramos pretensiones de estatus y poder aunadas a una indiferencia respecto al daño que con sus operaciones puedan hacer a varios ámbitos de la Ley y de la sociedad en su conjunto ${ }^{78}$.

\section{A) Los Efectos Negativos del Tráfico de Drogas en el Mundo Contemporáneo}

Se puede advertir que la drogadicción constituye en la actualidad un grave problema de salud pública de orden mundial. Según un informe de Naciones Unidas, 185 millones de personas consumen drogas ilegales en el mundo, de las cuales 147 millones son consumidores de cannabis, 33 millones de anfetaminas, 7 millones éxtasis, 13 millones de cocaína y 13 millones de opiáceos (9 millones de heroína) ${ }^{79}$.

Especialistas y órganos internacionales - como en la Convención de Viena contra el tráfico ilícito de estupefacientes (1988) - , expresan que el consumo de droga no solo representa un fenómeno social que atenta contra la salud pública - de millones de consumidores en todo el mundo-, sino que con su producción ilegal y su tráfico se usocavan las economías lícitas y amenazan la estabilidad y la soberanía de los Estados»" ${ }^{80}$. Señalan que respaldadas en sus grandes beneficios económicos ${ }^{81}$ "las organizaciones

${ }^{75}$ Cf. GarCía-PAblos de Molina, Antonio, "Criminología. Una introducción a sus fundamentos teóricos para juristas», Tirant lo blanch, Valencia, 1992, p. 86.

${ }^{76}$ Ob. ult. cit.

${ }^{77}$ Vid. Herrero Herrero, César, "Criminología. Parte General y Especial», cit., p. 549.

${ }^{78}$ HerRero HerRero, César, «Criminología. Parte General y Especial», cit., p. 556.

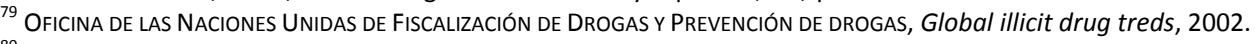

${ }^{80}$ El tráfico de drogas financiado por el crimen organizado desajusta las economías de países enteros, atenta contra las instituciones legales y amenaza la seguridad misma de algunos Estados. En tales países las políticas represivas no obtienen mejores resultados que en EEUU. Como señala un autor: «las campañas antidrogas garantizan inestabilidad e inseguridad». Cf. MARSHALLS, Jonathan, «Drogas y la Política Exterior Norteamericana», en Tráfico y consumo de drogas, Unión, Madrid, 1991, p. 168.

${ }^{81}$ El volumen real de estos beneficios económicos no se conoce con exactitud, únicamente se especula en grandes cifras, las que se establecen tomando como base los siguientes indicios o elementos: a) los bienes muebles e inmuebles que se incautan e intervienen a los traficantes, el dinero, cuentas corrientes y ahorro, divisas, etc., y b) la cantidad de estupefaciente decomisado y el valor medio que alcanza en el mercado español. Vid. YÉBENES GADEA, Antonio, «El proceso económico del tráfico ilícito de drogas en España y sus consecuencias», Revista Ciencia Policial., No. 21, abril-junio 1993, Dirección General de Policía, Madrid, p. 47.

$$
\sim 36 \sim
$$


internacionales, dedicadas a tal tráfico, invaden, contaminan y corrompen las estructuras administrativas públicas, las actividades comerciales y financieras lícitas.... ${ }^{82}$.

Hoy nadie discute que el tráfico de drogas - efectuado por grandes organizaciones de criminalidad organizada - ha logrado infiltrarse en todos los rincones de la sociedad internacional, en sectores políticos, económicos y culturales ${ }^{83}$. No se podría explicar esta situación sin la presencia de ciertos intereses políticos y económicos que inciden en el tráfico internacional de sustancias tóxicas ${ }^{84}$. Cabe resaltar que los factores económicos - por encima de otros- se han constituido como el verdadero motor que ha impulsado tal actividad ilícita en todo el planeta, al grado que este elemento ha sido crucial al momento de decidir sobre la legalidad o ilegalidad de estas acciones ${ }^{85}$.

El factor económico se refleja de manera importante en las exorbitantes ganancias anuales generadas por la venta de estupefacientes en todo el mundo. Como se ha señalado, tales cifras se sitúan entre $\mathbf{3 0 0 . 0 0 0}$ y $\mathbf{5 0 0 . 0 0 0}$ millones de dólares. Se piensa que más del $\mathbf{5 0 \%}$ de esta cantidad es infiltrada en el mercado legal a través de circuitos financieros legales ${ }^{86}$. Para finales de los años ochenta, ya se estimaba que el volumen del mercado clandestino de estupefacientes representaba $9 \%$ del comercio mundial. Ante tales números, podemos ir especulando, desde este momento, los graves peligros que representa el volumen de estos capitales ilícitos para la estabilidad de la economía mundial, así como para la transparencia y credibilidad de las instituciones financieras internacionales ${ }^{87}$.

Las razones de fondo que incitan a las mafias internacionales a entrar en circuitos financieros formales, o en su caso en la producción de bienes y servicios legales, no se vincula únicamente a la necesidad de reconvertir sus capitales ilícitos. Se ha comprobado que, junto a esta motivación la tendencia de los cárteles a reinvertir sus beneficios económicos, concurren las circunstancias que se indican a continuación:

${ }^{82}$ Vid. NACIONES UNIDAS. Convención de las Naciones Unidas contra el tráfico ilícito de estupefacientes y sustancias psicotrópicas, Viena Austria, 20 de diciembre de 1988 y BOE de 10 de noviembre de 1990.

${ }^{83} \mathrm{VId}$. ANARTE BORALLO, Enrique, "Conjeturas sobre la criminalidad organizada», en Delincuencia organizada. Aspectos penales y criminológicos, FerRé Olivé, Juan Carlos/ Universidad de Huelva/Fundación El Monte, Huelva, 1999, pp. 15 ss.

${ }^{84} \mathrm{Vid}$. BeRISTAIN, Antonio, "Dimensiones histórica, económica y política del tráfico de las drogas en la criminología crítica», en Delitos contra la salud pública. Tráfico ilegal de drogas tóxicas o estupefacientes, Colección de Estudios de estudios. Instituto de Criminología y Departamento de Derecho Penal, Valencia 1977, p. 73 y ss.

${ }^{85}$ En el pasado, tal y como ocurre en la actualidad, el factor económico fue el decisivo a la hora de decidir sobre la legalidad del tráfico y uso de una droga; como prueba de esta afirmación, se señalan los siguientes antecedentes: a) España, en la Época de la colonización, obtuvo importantes ventajas de la venta y comercio de algunas; b) en el siglo XIX Europa conocía los peligros de ciertas sustancias, pero no reprobó su consumo, en cierta forma por las ventajas económicas que suponía; c) Occidente, durante varios siglos, y particularmente durante el siglo XIX, por claras razones económicas, monopolizó las producción y venta de diversos tipos de drogas; d) a comienzos del siglo XX, la mitad de los ingresos públicos de Inglaterra provenían del comercio monopolizado de opio; e) Francia durante la primera mitad del siglo XX logró enormes beneficios de Indochina, con la importación, manufactura y comercio de opio, y f) en el presente, aunque generalmente omitido en los discursos oficiales, el factor económico influye en la problemática de la droga. El tráfico de drogas es, sustancialmente, un negocio de alta rentabilidad. Las motivaciones económicas han sido determinantes para la inclusión de ciertas sustancias en las listas de las prohibidas. Éstas razones influyen más que las que las políticas, sanitarias o morales. Se prohíben drogas que para determinadas economías son improductivas. Cf. PRIETO RODRíGUEZ, Javier Ignacio, «El delito de tráfico y el consumo de drogas en el ordenamiento jurídico penal español», cit., pp. 635-637.

${ }^{86}$ Vid. FABIÁn CAPARRós, Eduardo, «El delito de blanqueo de capitales», Colex, Madrid, 1998, p. 30, Quien comenta que las diferencias entre el monto mínimo y máximo de estas cifras, es debido a las dificultades con las que nos encontramos al momento de intentar establecer con exactitud la realidad económica que rodea a este delito. Aunque hay otros organismos que no comparten el parámetro mínimo de la ONU, como el Departamento del Tesoro de los EEUU y el Parlamento Europeo, los que calculan directamente en los 500.000.000.000 de dólares la cifras económicas que mueve el narcotráfico anualmente. Información cit. por: GARZón, Baltasar, "El delito de blanqueo de capitales en la legislación española», en Drogas, Desarrollo y Estado de Derecho, Instituto Deusto de Drogodependencias, Universidad de Deusto, Bilbao, 1995, p. 135.

${ }^{87}$ Vid. Vega SeRRANo, Juan Manuel, «Drogas y economía: aspectos financieros del tráfico de drogas», en: Drogodependencia y derecho, No. VIII, Cuadernos de Derecho Judicial, Consejo General del Poder Judicial, Madrid, 2003, pp. 147 y ss.

$$
\sim 37 \sim
$$


a) Los clanes mafiosos, debido a la infraestructura operativa con la que disponen y los procedimientos que utilizan habitualmente (que van desde la violencia hasta la corrupción), tienen mayores recursos para penetrar en las actividades económicas legales - que los que poseen las personas que respetan la norma - , por lo que aprovechan esta circunstancia para obtener mayores beneficios, $y$

b) En muchos de los casos existe la necesidad "política» del crimen organizado de fomentar actividades legales capaces de asegurar trabajo y sustento de la población que vive en las regiones en las que las organizaciones criminales despliegan control territorial ${ }^{88}$.

Todo parece indicar que las elevadas ganancias que generan el tráfico mundial de estupefacientes, la infiltración de esos beneficios en los circuitos financieros, la forma de operar de la moderna delincuencia organizada - cada vez más inmiscuida en actividades legales-, así como la estructura socioeconómica y política del mundo contemporáneo, son elementos que convergen para que el tráfico internacional de drogas represente, en términos globales y por encima del problema sanitario, una amenaza para la estabilidad política y económica del mundo ${ }^{89}$.

A continuación, describiremos - brevemente- algunos de los riesgos que supone para las instituciones financieras y políticas del mundo la dimensión criminógena del tráfico de drogas.

\section{B) Los Capitales de la Droga: un Peligro para las Instituciones Financieras y Políticas del Mundo}

Las ganancias obtenidas del tráfico ilícito de drogas no solo son utilizadas por los narcotraficantes como sustento para continuar sus operaciones ilícitas y costear su alto nivel de vida, también son usadas para establecer una influencia en el contexto institucional -en los poderes ejecutivo, legislativo y judicial- ${ }^{90}$ con el fin de aproximarse a los cuerpos policiales, servicios de aduanas, hacienda y, en general, a cualquier estamento cuyo control resulte necesario para adquirir mayor poder y seguridad en sus operaciones $^{91}$. Igualmente, las ganancias son útiles para infiltrarse en los sectores bancarios, de transporte, distribución, hostelería o cualquier otro segmento de la producción o servicios ${ }^{92}$, así como para allegarse a roles y actividades de prestigio social - los grandes traficantes de drogas aspiran a ser personas de buena imagen social e incluso a ser propuestos como modelos de personas exitosas- y ejercer influencia en los medios de comunicación -ya sea indirectamente, por coacción o adquiriéndolos ${ }^{93}$.

Dado lo anterior, resulta fácil comprender la tendencia - cada vez más común- que tiene la moderna delincuencia organizada a reinvertir el dinero producto de sus operaciones ilegales. Por otro lado, la magnitud de tales capitales es capaz de alterar las reglas de funcionamiento de mercado, los

${ }^{88}$ Respecto al último aspecto, hay que rechazar la errónea visión - que deriva de una visión mitológica de la mafia -, de que la economía ilegal aporta puestos de trabajo y bienestar a la economía lícita y los gobiernos no han sido capaces de materializar en determinadas zonas, como en el típico caso del Sur de Italia: en el que se ha comprobado que la mafia no es un efecto del retrazo económico de estas zonas, sino más bien, una de sus causas. Cf. FOFFANI, Luigi, «Criminalidad organizada y criminalidad económica», RP, No. 7, La Ley, enero de 2001, pp. 59 y 60.

${ }^{89}$ Vid. Herrero Herrero, César, "Delincuencia económica al amparo del fenómeno de la droga», Boletín de Información del Ministerio de Justicia, n. ${ }^{\circ} 1522$, (25-3-89), Madrid, p. 1291

${ }^{90}$ Vid. GURIDI, L., «Narcotráfico y desarrollo», Drogas, Desarrollo y Estado de Derecho, Universidad de Deusto, Bilbao, 1995, p. 85.

${ }^{91}$ Vid. UPRIMnY, Rodrigo, "Notas sobre el fenómeno del narcotráfico en Colombia», en Drogas y control penal en los Andes. Deseos, Utopías y efectos perversos, Comisión Andina de Juristas, Lima, 1994, pp. 260 y ss.

${ }^{92}$ Vid. BLIXEN, Samuel, «El dinero de la droga y la droga del dinero. La banca latinoamericana y el narcotráfico», en El planeta de las drogas. Organizaciones criminales, guerras y blanqueo de dinero, Mensajero, Bilbao, 1994, pp. 212 y ss.

${ }^{93}$ Vid. FUENTES GONZÁLEZ, Gabriel, «El proceso económico del tráfico ilícito de drogas», Revista Ciencia Policial n. ${ }^{\circ} 63$, mayo-junio 2002, Dirección General de Policía, Madrid, p. 13. 
propios modelos de inversión, la desertización productiva, provocando dificultades para crear riqueza sólida al tener tanta influencia en los agentes de la decisión económica ${ }^{94}$.

El crecimiento y expansión actual de las mafias de la droga supera su carácter meramente territorial hasta convertirse en una seria amenaza para la estabilidad política y económica de las naciones democráticas $^{95}$. De igual forma, el debilitamiento de la organización estatal y las instituciones públicas, la pérdida de capacidad para garantizar el cumplimiento de la legalidad y la inevitable corrupción que ha surgido dentro de sus poderes políticos, han contribuido en gran medida a la expansión e internacionalización de estas organizaciones criminales formando así un círculo vicioso ${ }^{96}$.

Tanto el comercio ilegal de mercancías como la economía de los narcóticos han aprovechado las actuales circunstancias de recesión económica y de reestructuración de las economías nacionales bajo el programa de ajuste del Fondo Monetario Internacional (FMI) y el Banco Mundial (BM) en el sur y el este. Asimismo, el debilitamiento de los mercados internos y de exportación, la destrucción de economías, la globalización de la pobreza, la política basada en el préstamo de países ricos y el endeudamiento de los países deudores, la privatización de la propiedad agrícola y empresas públicas, la venta de compañías mercantiles estatales, los cambios en el sistema monetario y la liberación del sistema bancario ${ }^{97}$, ofrecen un ambiente global de recesión de la "economía legal», que favorece, por una parte, a la infiltración de las mafias al sistema económico mundial, y por otra, el vertiginoso crecimiento y perfeccionamiento del comercio y la producción ilícitas ${ }^{98}$.

\section{C) El Tráfico de Drogas un Germen que se Alimenta de la Crisis Económica del Tercer Mundo}

Cada vez es más común que las reformas y las políticas económicas impuestas por el FMI y el BM tengan -como en el caso de Yugoslavia y la antigua URSS - consecuencias económica y políticamente

${ }^{94}$ Ob. ult. cit., pp.13 y 14.

${ }^{95} \mathrm{Vid}$. ZARAgOZA AgUADO, Javier, "Tratamiento penal y procesal de las organizaciones criminales en el Derecho español. Especial referencia al tráfico ilegal de drogas», en: Delitos contra la salud pública y contrabando, en Cuadernos de Derecho Judicial, Consejo General del Poder Judicial, Madrid, 2000, pp. 52 y 53.

${ }^{96}$ Vid. GarRido, Vicente, Stangeland, Per y Redondo, Santiago, «Principios de Criminología», 2a ed., Tirant lo blanch, Valencia, 2001, p. 683.

${ }^{97}$ Vid. CHOSSUDOWSKY, Michel, "EL FMI y el dinero de la droga», El planeta de las drogas. Organizaciones criminales, guerras y blanqueo de dinero, Mensajero, Bilbao, 1994, pp. 156 y ss.

${ }^{98}$ Vid. CHOSSUDOWSKY, Michel, "Deuda global, política macroeconómica y lavado de dinero», en Drogas, Desarrollo y Estado de Derecho, Universidad de Deusto, Bilbao, 1995, pp. 25 y ss. Con respecto de este punto, cabría citar las observaciones de FABIÁN CAPARRÓs, Eduardo A., "El delito de blanqueo de capitales», cit., p. 45, en las que afirma que: la delincuencia organizada representa en determinados países una cuota tan importante de su actividad económica, tanto en el ámbito ilícito $-v$. $g$., la producción de sustancias cuales son la heroína y la cocaína - como en el lícito -y así, el elevadísimo porcentaje de la Renta Nacional de ciertos países que procede del afloramiento de los rendimientos de tales conductas delictivas - que bien podría decirse que la pervivencia de esas mafias condiciona el mantenimiento de amplísimos estratos sociales».

Por otro lado, en algunas naciones es tan grande la influencia de las organizaciones criminales que algunos autores las definen como: "verdaderos contrapoderes, antagónicos y paralelos a los poderes legales». Vid. TURONE, Giuliano, L'impostazione dell'inchiesta sulla criminalità organizatta. Manuale pratico dell'Inchiesta Penale, Giuffrè Editore, Milano, 1986. Cit. a pie de página por: ZARAGOZA AGUADO, Javier, «Tratamiento penal y procesal de las organizaciones criminales en el Derecho español. Especial referencia al tráfico ilegal de drogas», en Delitos contra la salud pública y contrabando, edit. Cuadernos de Derecho Judicial, Consejo General del Poder Judicial, Madrid, 2000, p. 55.

La disfuncionalidad económica y política provocada por el tráfico ilícito de estupefacientes en varios países, ha provocado que el Plan de Acción Global contra la Delincuencia Organizada -aprobado por el Consejo de Ámsterdam en junio de 1997, y que se puede entender como el programa político-criminológico de la Unión Europea para el tratamiento de esta problemática-, en una de sus treinta recomendaciones, establezca, la necesidad de adoptar una política global contra la corrupción y fortalecimiento de la transparencia de las administraciones públicas y de las empresas privadas, buscando con ello evitar la participación de organizaciones criminales en los procedimientos de contratación pública, recepción de subsidios o licencias gubernamentales; así como a recomendar que se favorezca la participación más activa de las profesiones liberales y otras profesiones particularmente expuestas a la influencia de la delincuencia organizada. 
devastadoras. Paradójicamente, con su aplicación se ha fomentado una alteración en las actividades sociales fundamentales provocando una criminalización de la actividad económica, saqueo de la propiedad estatal, reconversión de dinero negro y evasión de capitales ${ }^{99}$. De la misma forma, la reestructuración de la economía mundial promovida por las instituciones financieras internacionales, ha favorecido al empobrecimiento de los países en vías de desarrollo convirtiéndolos en territorios cuya única competitividad económica deriva de la mano de obra barata que pueden ofrecer y de la explotación de los recursos naturales con los que cuentan.

La expansión de las actividades ilícitas como alternativa y la narco-economía, están estrechamente vinculados con este proceso de colapso económico y mundial ${ }^{100}$, como se observa en el caso de los países andinos (Bolivia y Perú específicamente), que sufren lacerantemente los efectos de las políticas económicas de ajuste neoliberal, en donde a los campesinos no les queda otro camino que la producción de la hoja de coca para enfrentar la pobreza ${ }^{101}$. De esta manera, un negocio ilegal termina fungiendo un papel fundamental en lo económico, político y social de algunos países. ${ }^{102}$

La crisis en la que está inmersa la economía mundial y las transformaciones experimentadas en la esfera productiva, comercial y financiera, han tenido desastrosos efectos en la mayor parte de los países del tercer mundo, si no es que en todos. El detrimento en los términos de intercambio, el desplome generalizado de la renta y la pérdida del poder adquisitivo por parte de los trabajadores, es un denominador común para gran parte de África, Europa del Este, Asia y Latinoamérica ${ }^{103}$.

En todo el tercer mundo la economía experimenta una crisis que facilita la inmersión de capitales ilícitos en importantes sectores de la economía, como en América Latina, el fracaso del modelo de sustitución de importaciones y la crisis de la deuda externa, el deterioro de los términos de intercambio y la pérdida del salario real, han contribuido para que paralelamente, y a la sombra de esta disfuncionalidad económica, se expandan la producción y el tráfico de estupefacientes por toda la región, al grado de que la mayoría de sus países, de alguna forma, ya sean parte activa en la larga cadena del tráfico internacional de sustancias tóxicas ${ }^{104}$.

${ }^{99}$ Vid. CHOssudowskY, Michel «Deuda global, política macroeconómica y lavado de dinero», cit., p. 29.

${ }^{100}$ Ob. ult. cit., p. 30.

${ }^{101}$ Vid. HeRRADA, David, «Con la hoja de coca combatimos el hambre», en Drogas, Desarrollo y Estado de Derecho, Universidad de Deusto, Bilbao, 1995, p. 55. Esta pobreza en la región, seguirá agudizándose, mientras no se ofrezcan programas y proyectos de desarrollo alternativo que ayuden a reducir la dependencia que tiene estas naciones del cultivo ilegal de estupefacientes. Vid. OLESTI RAYo, Andrés, "La Unión Europea y la reducción de la oferta ilícita de drogas», Revista de Derecho Comunitario Europeo, año 6, No. 11, Centro de Estudios Políticos y Constitucionales, Madrid, enero-abril, 2002, p. 151.

En otro sentido, el incremento del tráfico de cocaína en el denominado triángulo blanco (Perú, Bolivia y Colombia), se explica por la combinación de la gran demanda por parte de los países desarrollados y por la existencia de miles de campesinos pobres, sin alternativas, dispuestos a cultivar la hoja de coca a pesar de la ilegalidad y la prohibición que lleva consigo dicha actividad. Vid. ESPINAZO GARCía, Juan, y Molina ESTRELLA, Araceli, «Dimensiones del narcotráfico internacional», cit., p. 93.

${ }_{102}$ Vid. HeRRADA, David, "Con la hoja de coca combatimos el hambre», en Drogas, Desarrollo y Estado de Derecho, Universidad de Deusto, Bilbao, 1995, pp. 55 y ss.

${ }^{103}$ Vid. GURIDI, L., «Narcotráfico y desarrollo», Drogas, Desarrollo y Estado de Derecho, Universidad de Deusto, Bilbao, 1995, p. 85.

${ }^{104}$ Su forma de participar estas naciones en el tráfico internacional de estupefacientes, en términos generales, es: Bolivia, Perú, Colombia, Ecuador, Guatemala, México y Brasil en la producción; Argentina en la transformación; Chile, Venezuela. Belice, Surinam, Panamá, Haití, Puerto Rico y El Salvador en el tránsito; Venezuela, Panamá, Uruguay, Chile e Islas Caimanes, en el blanqueo. Comentando un poco sobre esta misma situación en otras partes de mundo, encontramos que también la fuerte crisis económica del África ha influido para que varios países se introduzcan en la industria de la droga: como es el caso de Laos, Costa de Marfil, Nigeria, Chad, Senegal, Liberia, Benin o Zaire. A las que debemos sumar las tradicionales zonas de producción del norte del continente africano, especialmente Marruecos, al que se le suman casi todos los países de la parte central de África en la producción de hachís. También, se han encontrado intentos de plantación de coca en el norte de Nigeria, Camerún, República Centro Africana, Uganda y Kenia. Brevemente, por lo que toca a Asia, donde se encuentran las dos mayores zonas de producción Mundial de opio y heroína: India, Irán, Camboya, Pakistán, Tailandia, Filipinas y China participan, en la producción; Hong Kong, Singapur y Taiwán en el tránsito y lavado de dinero. Por último, refiriéndonos a Europa del Este, la profunda crisis económica, política y social que sufren estas naciones, ha permitido la instalación definitiva de mafias que participan en el tráfico internacional de drogas tóxicas, principalmente en las $\sim 40 \sim$ 
Revista Jurídica del Departamento de Derecho Academia de Derecho Administrativo

Tercera Época Año2. No. 3 / Julio-Diciembre 2010

\section{D) Los Beneficios Económicos del Tráfico de Drogas. Sombra para el Sistema Financiero Internacional}

Un especialista en criminalidad económica afirma que el tráfico de drogas exhibe una particularidad entre todas las actividades criminales: «no puede ejercer más con la ayuda casi diaria de un sector económico legal que es el sector bancario ${ }^{105}$. Al día de hoy, las transferencias bancarias y el reciclaje internacional de las ganancias ilícitas se han cristalizado como una de las características esenciales del sistema financiero mundial ${ }^{106}$. A nivel macro-económico es incuestionable que los negocios legales e ilegales están cada vez más interconectados; cada vez es más patente la influencia que las mafias financieras ejercen sobre el control de los principales intereses bancarios ${ }^{107}$. Al reverso de la moneda, la actividad comercial reglamentada se involucra en la economía criminal por medio de la adquisición de bancos, sociedades comerciales, etc., que están implicadas en la legitimación de capitales de origen ilícito y tienen vínculos directos con mafias internacionales. El procedimiento funciona en ambas direcciones: los cárteles (con intereses en la narcoeconomía y el comercio ilegal) reciben bienes productivos y bancarios de la economía legal y ésta, por su parte, tiene un franco soporte en la ilícita ${ }^{108}$.

E) Infiltración del Narcotráfico en las Actividades del Estado y en los Procesos de Privatización de sus EMPRESAS

El proceso de infiltración en actividades legales por parte de organizaciones criminales que trafican con droga también perjudica a la estructura del Estado, comprobándose que destacadas personalidades políticas y antiguos funcionarios de los Gobiernos tienen lazos con grupos mafiosos ${ }^{109}$. Situación que genera que en ocasiones, en determinados países, se presente una "desviación" en las ordenaciones políticas ${ }^{110}$, las cuales tienen una vinculación inmediata en la política hecha por los gobiernos incluyendo la de su reforma financiera y macroeconómica. Las mafias constituyen, cada vez con mayor regularidad, influyentes grupos secretos de presión en varias naciones, interviniendo en los objetivos y orientación de la política oficial.

Los capitales del narcotráfico se han inmiscuido en los procesos de privatización de empresas públicas de Latinoamérica y con ello "resuelven» un verdadero problema para las administraciones de algunos países, pues requieren -imperiosamente- un derrame permanente de divisas para hacer frente

repúblicas de Uzbekistán y Kazajstán en Ucrania, que participan en la producción de adormidera y cannabis; en esta zona del globo podemos encontrar, laboratorios de producción de heroína, drogas de síntesis, todo tipo de mafias para el transporte, comercialización y reciclaje de capitales. Cf.. GURIDI, L., "Narcotráfico y desarrollo», cit., pp. 85 y 86 . Vid. También: UPRIMNY, Rodrigo, «Notas sobre el fenómeno del narcotráfico en Colombia», cit., pp. 260 y ss.

${ }^{105}$ Cf. BufFLE, Jean Claude, «Bancos suizos y traficantes colombianos», en: Drogas, Desarrollo y Estado de Derecho, Universidad de Deusto, Bilbao, 1995, p. 132. Quien comenta que: «sin duda alguna, los banqueros son también útiles a los traficantes de armas y a los terroristas; pero ni el tráfico de armas ni las actividades terroristas poseen el carácter de constancia o necesidades relativas al capital que presenta el tráfico de droga».

${ }^{106}$ Vid. VeGA SERRANO, Juan Manuel, «Drogas y economía: aspectos financieros del tráfico de drogas», cit., pp. 145 y ss.

107 Vid. CHOSsudowsky, Michel "Deuda global, política macroeconómica y lavado de dinero», cit., p. 26. Como comenta otro autor, las ganancias ilícitas del crimen organizado constituyen un gran poder económico para el que pueda disponer de ellas. Esencialmente, cuando está materializado en dinero en efectivo, o por transacciones bancarias o cuando ha sido transformado en cualquier otro instrumento de pago reinvertible en la economía legal. Vid. BotTKE, Wilfried, «Mercado, criminalidad organizada, y blanqueo de dinero en Alemania», Revista Penal, n. ${ }^{\circ}$ 2, Praxis, Barcelona, julio de 1998, pp. 2 y 3.

108 Vid. CHOSSUDOWSKY, Michel «Deuda global, política macroeconómica y lavado de dinero», cit., p. 26.

${ }^{109}$ Hasta el punto de desestabilizar los fundamentos sobre los que descansa el Estado de derecho; por ello no resulta absurdo hablar de que, en ciertas zonas, se forman «pequeños Estados dentro del Estado». IGLESIAs Ríos, Miguel Ángel, «Criminalidad organizada y delincuencia económica. Aproximación a su incidencia global», cit., p. 28.

${ }^{110}$ Vid. UPRIMNY, Rodrigo, «Notas sobre el fenómeno del narcotráfico en Colombia», cit., p. 269.

$$
\sim 41 \sim
$$


a los compromisos asumidos en las refinanciaciones de la deuda externa ${ }^{111}$. Tales compromisos internacionales, y las propias prioridades locales, han alentado la multiplicación de este tipo de operaciones - de blanqueo de capitales- por todo el continente ${ }^{112}$.

La producción de sustancias tóxicas y su consecuente tráfico, son un negocio dinámico con una gran capacidad de acumulación rápida de recursos. Esa formación vertiginosa de beneficios facilita la formación de bloques de poder. Por las circunstancias actuales de pobreza y las estrategias económicas que hoy imperan, ese bloque de poder extiende vorazmente su influencia en gran parte del mundo, al grado tal que en muchos casos desconocemos las fronteras de quién maneja a quién en la economía ilegal de las drogas ${ }^{113}$.

\section{CONCLUSIONES}

Actualmente, la drogadicción constituye en la actualidad no solo un problema de seguridad pública, sino un grave problema de salud pública de orden mundial, que además socava las economías lícitas y amenazan la estabilidad y la soberanía de los Estados que contaminan y corrompen las estructuras administrativas públicas, las actividades comerciales y financieras lícitas.

El tráfico de drogas efectuado por grandes organizaciones de criminalidad organizada que se encuentra infiltrado en todos los rincones de la sociedad internacional, en sectores políticos, económicos y culturales, no se podría explicar sin la presencia de ciertos intereses políticos y económicos que inciden en el tráfico internacional de sustancias tóxicas.

Las ganancias obtenidas del tráfico ilícito de drogas no solo son utilizadas por los narcotraficantes como sustento para continuar sus operaciones ilícitas y costear su alto nivel de vida, también son usadas para establecer una influencia en el contexto institucional en los poderes ejecutivo, legislativo y judicial, con el fin de aproximarse a los cuerpos policiales, servicios de aduanas, hacienda y, en general, a cualquier estamento cuyo control resulte necesario para adquirir mayor poder y seguridad en sus operaciones.

Las ganancias son útiles para infiltrarse en los sectores bancarios, de transporte, distribución, hostelería o cualquier otro segmento de la producción o servicios, así como para allegarse a roles y actividades de prestigio social y ejercer influencia en los medios de comunicación.

La producción de sustancias tóxicas y su consecuente tráfico, son un negocio dinámico con una gran capacidad de acumulación rápida de recursos.

\section{BibLIOgRAFÍA}

ANARTE Borallo, Enrique, "Conjeturas sobre la criminalidad organizada", en Delincuencia organizada. Aspectos penales y criminológicos, FERRÉ OLIVÉ, Juan Carlos/ Universidad de Huelva/Fundación EI Monte, Huelva, 1999.

Beristain, Antonio, «Dimensiones histórica, económica y política del tráfico de las drogas en la criminología crítica», en Delitos contra la salud pública. Tráfico ilegal de drogas tóxicas o

${ }^{111}$ Cf. BLIXEN, Samuel, «El negocio de la droga: socio del neoliberalismo», en Drogas, Desarrollo y Estado de Derecho, Instituto Deusto de Drogodependencias, Universidad de Deusto, Bilbao, 1995, p. 114.

112 Ob. ult. cit., p. 113

${ }^{113}$ Como señala al respecto algún autor: «se tiende a pensar que los narcotraficantes compran a políticos, jueces y comandantes y corrompen al sistema. Acaso el sistema, decidido a asumir la corrupción como componente inevitable, fomenta esa ilusión». Ob. ult. cit., p. 114. 
Revista Jurídica del Departamento de Derecho Academia de Derecho Administrativo

Tercera Época Año2. No. 3 / Julio-Diciembre 2010

estupefacientes, Colección de Estudios de estudios. Instituto de Criminología y Departamento de Derecho Penal, Valencia 1977.

BLIXEN, Samuel, "El dinero de la droga y la droga del dinero. La banca latinoamericana y el narcotráfico», en El planeta de las drogas. Organizaciones criminales, guerras y blanqueo de dinero, Mensajero, Bilbao, 1994.

— «El negocio de la droga: socio del neoliberalismo», en Drogas, Desarrollo y Estado de Derecho, Instituto Deusto de Drogodependencias, Universidad de Deusto, Bilbao, 1995.

BotTKE, Wilfried, «Mercado, criminalidad organizada, y blanqueo de dinero en Alemania», Revista Penal, n. ${ }^{\circ}$ 2, Praxis, Barcelona, julio de 1998.

BuffLE, Jean Claude, «Bancos suizos y traficantes colombianos», en: Drogas, Desarrollo y Estado de Derecho, Universidad de Deusto, Bilbao, 1995.

Chossudowsky, Michel, "Deuda global, política macroeconómica y lavado de dinero", en Drogas, Desarrollo y Estado de Derecho, Universidad de Deusto, Bilbao, 1995.

- «EL FMI y el dinero de la droga», El planeta de las drogas. Organizaciones criminales, guerras y blanqueo de dinero, Mensajero, Bilbao, 1994.

Escohotado, Antonio, «Historia de las Drogas», tomo III, Alianza, Madrid, España. 1989.

Espinazo García, Juan, "La Droga. Perspectiva criminológica», Publicaciones del Instituto de Criminología de la Universidad Complutense de Madrid, 1980.

- y Molina eSTRELLA, Araceli, «Dimensiones del narcotráfico internacional», editora Araceli Molina estrella, Madrid, 2001.

FABIÁn CAPARRós, Eduardo, «El delito de blanqueo de capitales», Colex, Madrid, 1998.

FofFANI, Luigi, «Criminalidad organizada y criminalidad económica», RP, No. 7, La Ley, enero de 2001.

Fuentes GonzÁlez, Gabriel, «El proceso económico del tráfico ilícito de drogas», Revista Ciencia Policial n. 63, mayo-junio 2002, Dirección General de Policía, Madrid.

GARcía RAmírez, Efraín, «Drogas. Análisis del delito contra la salud», SISTA, 3a ed., México, 1997.

García-Pablos de Molina, Antonio, «Criminología. Una introducción a sus fundamentos teóricos para juristas», Tirant lo blanch, Valencia, 1992.

Garrido, Vicente, Stangeland, Per y Redondo, Santiago, “Principios de Criminología», 2ª ed., Tirant lo blanch, Valencia, 2001.

Garzón, Baltasar y Megías, Eusebio, «Narco. El tráfico de drogas como instrumento del crimen organizado. La presencia de las drogas: razones, riesgos y límites», Germania, Barcelona, 1997.

GARzón, Baltasar, "El delito de blanqueo de capitales en la legislación española», en Drogas, Desarrollo y Estado de Derecho, Instituto Deusto de Drogodependencias, Universidad de Deusto, Bilbao, 1995.

GURIDI, L., «Narcotráfico y desarrollo», Drogas, Desarrollo y Estado de Derecho, Universidad de Deusto, Bilbao, 1995. 
HerRada, David., "Con la hoja de coca combatimos el hambre", en: Drogas, Desarrollo y Estado de Derecho, Instituto Deusto de Drogodependencias, Universidad de Deusto, Bilbao, 1995.

Herrero Herrero, César, "Criminología. Parte General y Especial», 1a y 2a ed., Dykinson, Madrid, 1997 y 2001.

- "Delincuencia económica al amparo del fenómeno de la droga», Boletín de Información del Ministerio de Justicia, $n .^{\circ} 1522$, (25-3-89), Madrid.

IGLESIAS Ríos, Miguel Ángel, "Criminalidad organizada y delincuencia económica. Aproximación a su incidencia global», en Criminalidad organizada y delincuencia económica. (Estudios en homenaje al profesor Herney), Ediciones jurídicas Gustavo Ibáñez, Bogota, 2002.

LLORENS BoRRÁs, José Antonio, «La Droga y su Problemática Actual», Acervo, S. L., Barcelona, 1986.

Mapelli Cafarena, Borja; González Cano, Mạ Isabel, Aguado Correa, Teresa, «Estudios sobre la delincuencia organizada. Medios, instrumentos y estrategias de la investigación policial», Instituto Andaluz de Criminología/Mergablum, Sevilla, 2001.

MARSHALLS, Jonathan, "Drogas y la Política Exterior Norteamericana», en Tráfico y consumo de drogas, Unión, Madrid, 1991.

NúÑEZ PAZ, Miguel Ángel, «Delincuencia organizada y blanqueo de dinero. Algunos aspectos criminológicos. Especial referencia a la situación española», en Blanqueo de dinero y corrupción en el sistema bancario, Aquí la fuente no 38, Ediciones Universidad de Salamanca, Salamanca 2002.

NACIONES UNIDAS. Convención de las Naciones Unidas contra el tráfico ilícito de estupefacientes y sustancias psicotrópicas, Viena Austria, 20 de diciembre de 1988 y BOE de 10 de noviembre de 1990.

Oficina de las naciones Unidas de fiscalización de Drogas y Prevención de Drogas, Global Illicit Drug Treds, 2002.

Olesti RAYo, Andrés, "La Unión Europea y la reducción de la oferta ilícita de drogas», Revista de Derecho Comunitario Europeo, año 6, No. 11, Centro de Estudios Políticos y Constitucionales, Madrid, eneroabril, 2002.

Prado SaldarRiaga, Víctor, "La política criminal y el problema de la droga en Perú», en La actual política criminal sobre drogas. Una perspectiva comparada, José Luis Díez Ripollés y Patricia Laurenzo Copello (cords.), Tirant lo blanch, Valencia, 1993.

Prieto Rodríguez, Javier Ignacio, «El delito de tráfico y el consumo de drogas en el ordenamiento Español», 2a ed., Aranzadi, Pamplona, enero de 1993.

Roth, Jürgen y FREY, MARC, «Europa en las garras de la mafia», Anaya \& Mario Muchnik, Madrid, 1992.

STOCKLEY, David, «Drogas. Guía ilustrada», Edex, Bilbao, 1999.

Unidad Central de Estupefacientes, «Actuaciones del Cuerpo Nacional de Policía. Tráfico de drogas. 1998», en: CPol., No. 47, Instituto de Estudios de policía, Dirección General de Policía, Madrid, marzo-abril de 1999. 
UPRIMNY, Rodrigo, "Notas sobre el fenómeno del narcotráfico en Colombia», en Drogas y control penal en los Andes. Deseos, Utopías y efectos perversos, Comisión Andina de Juristas, Lima, 1994.

Vega Serrano, Juan Manuel, "Drogas y economía: aspectos financieros del tráfico de drogas», en: Drogodependencia y derecho, No. VIII, Cuadernos de Derecho Judicial, Consejo General del Poder Judicial, Madrid, 2003.

YÉbenes GADEA, Antonio, «El proceso económico del tráfico ilícito de drogas en España y sus consecuencias», Revista Ciencia Policial, No. 21, abril-junio 1993, Dirección General de Policía, Madrid.

Zaragoza Aguado, Javier, "Tratamiento penal y procesal de las organizaciones criminales en el Derecho español. Especial referencia al tráfico ilegal de drogas», en: Delitos contra la salud pública y contrabando, Cuadernos de Derecho Judicial, Consejo General. 